\title{
REVIEWS
}

PSychology of dementia PRAECox. By $C$. G. Fung, I907, Pp. I79

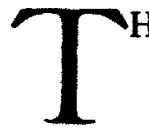

IIS valuable study is the result of three years' clinical work on dementia pracox and is an attempt to give a logical explanation of the behavior and utterances in this disease, which formerly were looked upon as strange and at random. It is certainly a healthy reaction from the vague auto-intoxication theories and the barren results of pathological anatomy. In no other disease, outside of hysteria, have purely psychological investigations yielded data of so much importance. Studies along these lines have laid bare the essential mental undercurrents, a claim which cannot be made for purely pathological studies, although the latter possess great value in certain directions. The poverty of the results and the contradictory nature of the work in the pathology of dementia praecox, has previously been pointed out by me (American Journal of Psychology, April, I905).

This recent monograph by Jung, submits to a searching analysis the essential psychological features of dementia pracox, sets forth the results of original work on the disease along the line of his well-known association studies and finally presents a review of previous psychopathological theories, such as the narrowing of the field of consciousness (Vogt), the theory of intrapsychic incoördination (Stransky), and of the dissociation of mental activity (Gross). The most striking new feature of the work is the attempt to trace the origin of individual symptoms, rather than to look upon these as strange, inexplicable behavior, the result of the lack of judgment and the primary apathy of the disease. Many of Jung's theories were however, antedated by Evenson and Stransky. Evenson found a close analogy between some of the prominent symptoms of dementia pracox, such as negativism, stereotypy, peculiar attitudes, etc., and the reactions of a normal person who has become preoccupied by one thought. He offered the suggestion that the essential features in both the preoccupied individual and in the katatonic are due to a narrowing of consciousness around a central content, and furthermore that there is a close analogy between hypnotic sleep and katatonic stupor. Stransky believes 
that the symptoms of dementia precox are due to what he terms an "intrapsychic incoördination" or a lack of inner unity between the understanding and the will. Careful analyses of the mental attitude of many of our patients have shown a peculiar blocking of thought, and a dissociation of the inner mechanism for will and action. Why in one case of mental dissociation there arises an hysterical complex and in another the symptoms of dementia precox furnishes a valuable field for study. This important point Jung has attempted to answer. His success can only be judged when we have accumulated further material that has been analyzed along the lines indicated by him. Within the limits of a review only the barest outlines of his theory can be given.

In hysteria the emotional activity has not ceased, but is merely suppressed, while in dementia pracox the opposite holds true; that is, the emotions are inhibited and destroyed, hence the striking emotional apathy. In both diseases, the essential mental undercurrents may be laid bare by studying the associations to a series of test words and taking the reaction time, thus forming what Jung calls "complex-indicators," indicating that the test word is closely related to some hidden complex. Many of the random replies in both hysteria and dementia pracox are due to a disorder of the mechanism of association. By a natural transition Jung then passes to the important point of the influence of the emotional thought-complex in the association of ideas. Here he introduces his well-known association studies that have proved so valuable in bringing to the surface hidden emotional undercurrents, whether these be voluntarily suppressed or involuntarily dissociated. He believes in the frequent symbolic expression of these hidden complexes, a symbolism which is best seen in dreams. In fact there is a striking analogy between the mechanism of dreams and the actions of a dementia-pracox patient. In both there is a distortion of thought and normal healthy activity, a kind of maladjustment to the $s$ oundings. When the underlying complexes control the e) re mental life we have dementia pracox, when they merely le en the amount of mental energy at the disposal of the patient, w' have hysteria. Thus there exists a close relationship betwi en dementia pracox and hysteria, especially in the various manifestations of the hidden complexes. This relationship is 
best seen in the strange anomalies of character, the general features of the mental dissociation and the narrowing of the field of consciousness, symptoms which are common to the two diseases.

\section{H. Coniat}

LA PSYChOTHERAPIE DANS sEs DIFFERENTS MODEs. $\boldsymbol{B}_{\boldsymbol{y}}$ A. W. Van Renterghem, Amsterdam, 1907, pp 184

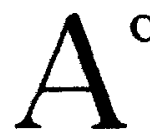

CCORDING to the author of this interesting little monograph, the psychological treatment of disease can be grouped into three different classes: First, psychotherapeutics proper, in which we console and encourage the patient, arouse in him the hope of a cure and attempt to remove from his mind his anxieties and morbid ideas. Second, psychic and motor re-education. Here we appeal to the intelligence of the patient, explain and analyze his paiticular disease to him, eliminate popular medical fallacies from his mind, modify his general mental attitude and in addition train certain muscles or muscular groups along normal coördinated lines. Third, direct suggestion, in which we attack the symptoms directly and implant in the mind the psychic image of cure.

The author then passes to a detailed discussion of hypnosis and replies to the various criticisms which condemn hypnotic suggestion. He does not agree with Dejerine and Dubois in substituting persuasion for suggestion. As the result of his own long experience he reaffirms the absolute innocuousness and freedom from danger of hypnotic suggestion in the hands of properly trained and properly qualified individuals. In many of the neuroses, hypnosis is not only more effective than persuasion, but its use actually lessens the period of treatment. This is a point of importance as many nervous patients are liable to become easily discouraged during a long course of treatment. In hysteria, neurasthenia, melancholia, obsess" 'is and hypochondriacal states, insomnia, phobias, etc. - treatment by suggestion is far more effective than treatment by persuasion. The author isolates his patient amid quiet and soothing surroundings and treats each patient individually contrary to Wetterstrand's practice. In spite of his criticism of 